\title{
Development and validation of RP-HPLC method for glimepiride and its application for a novel self-nanoemulsifying powder (SNEP) formulation analysis and dissolution study
}

\author{
Abdul Bari Mohd', Krishna Sanka², Rakesh Gullapelly², Prakash V Diwan ${ }^{1}$ and Nalini Shastri ${ }^{3^{*}}$
}

\begin{abstract}
Background: There are many analytical methods available for estimation of glimepiride in biological samples and pharmaceutical preparations. To our knowledge, there is no specific reverse-phase high-performance liquid chromatography (RP-HPLC) method for estimation of glimepiride and its dissolution study in self-nanoemulsifying powder (SNEP) formulation.

Methods: A simple method was carried out on a 5- $\mu \mathrm{m}$ particle octadesyl silane (ODS) column $(250 \times 4.6 \mathrm{~mm})$ with acetonitrile: $0.2 \mathrm{M}$ phosphate buffer $(\mathrm{pH}=7.4) 40: 60 \mathrm{~V} / \mathrm{v}$ as a mobile phase at a flow rate of $1 \mathrm{~mL} / \mathrm{min}$, and quantification was achieved at $228 \mathrm{~nm}$ using PDA detector.

Results: The correlation coefficient $\left(r^{2}\right)$ was found to be 0.999 over the concentration range of 0.2 to $2 \mu \mathrm{g} / \mathrm{mL}$ for glimepiride. The method was validated for linearity, accuracy, and precision. The limit of detection and limit of quantification were found to be 0.38 and $1.17 \mu \mathrm{g} / \mathrm{mL}$, respectively.

Conclusions: The proposed method was found to be simple, precise, suitable, and accurate for quantification of glimepiride as an alternative to the existing methods for the routine analysis of glimepiride in pharmaceutical formulations and in vitro dissolution studies.
\end{abstract}

Keywords: Glimepiride; Self-nanoemulsifying powder; RP-HPLC method; PDA detector; In vitro dissolution studies

\section{Background}

Glimepiride (GLM), a potent first III-generation sulfonylurea derivative is widely used in the treatment of non-insulin-dependent type II diabetes mellitus as an oral hypoglycemic agent (Langtry and Balfour 1998; McCall 2001; Rosenstock et al. 1996). Chemically, it is $1-\{(\mathrm{p}-[2-(3-\mathrm{ethyl}-4-$ methyl-2-oxo-3-pyrroline-1-carboxamide) ethyl] phenyl) sulfonyl\}-3-(trans-4-methylcyclohexyl) urea (Figure 1).

Like other sulfonylureas, GLM acts as an insulin secretagogue (Davis 2004) lowering blood glucose by stimulating insulin secretions from functioning pancreatic beta cells and by inducing extra-pancreatic effects (increasing sensitivity of peripheral tissues to insulin) thereby

\footnotetext{
* Correspondence: svcphod@yahoo.co.in

${ }^{3}$ Department of Pharmaceutics, National Institute of Pharmaceutical

Education and Research (NIPER), Hyderabad 500 037, AP, India

Full list of author information is available at the end of the article
}

decreasing the insulin resistance. GLM potentially binds to ATP-sensitive potassium channel receptors on the pancreatic beta cell surface, dropping potassium conductance across the membrane and causing depolarization of the membrane which stimulates calcium ion influx through voltage-sensitive calcium channels. This increase in intracellular calcium ion concentration induces the secretion of insulin. It can be employed for concomitant use with metformin, thiazolidinediones, alpha-glucosidase inhibitors and insulin for the treatment of noninsulindependent (type II) diabetes mellitus (Bell 2004). After oral administration, it is completely absorbed from the gastrointestinal tract. Severe hypoglycemic reactions with coma, seizure, or other neurological impairment are the possible toxic effects. Other side effects of sulfonylureas include nausea and vomiting, cholestatic jaundice, agranulocytosis, aplastic and hemolytic anemias, generalized 


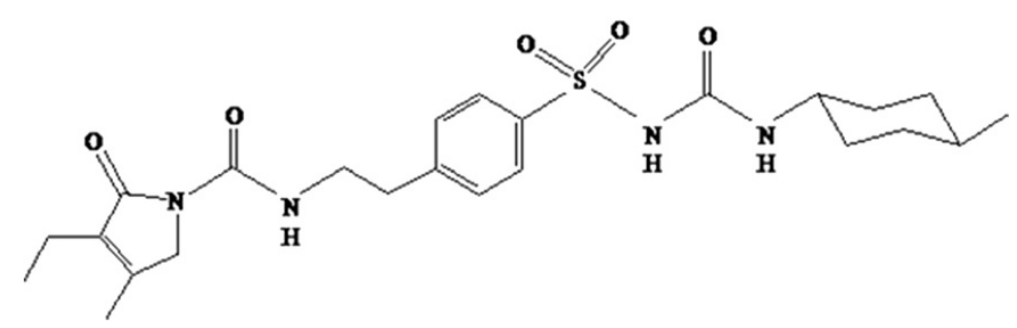

Figure 1 Structure of glimepiride.

hypersensitivity reactions, and rashes (Goodman and Gilman 2008).

Comprehensive literature survey revealed that quite a few diverse methods have been reported for qualitative and quantitative analysis of GLM in biological samples plasma/serum/urine and in pharmaceutical formulations containing single drug as well as in combination with other drugs. These include miceller electrokinetic capillary chromatography (MEEC) with diode-array detection (DAD) or ultraviolet (UV) detection (Nunez et al. 1995; Roche et al. 1997), high-performance liquid chromatography (HPLC) with DAD (Drummer et al. 1993) and UV detection (Jingar et al. 2008) and derivate UV spectrometric detection (Altinoz and Tekeli 2001), using semimicro bore high-performance liquid chromatography with column switching (Song et al. 2004), with pre-column derivatization (Lehr and Damm 1990), using monolithic column and flow program (El Deeb et al. 2006), HPLC-first derivative spectroscopy (Khan et al. 2009), reverse-phase high performance column chromatography (RP-HPLC, Sujatha et al. 2011; Wanjari and Gaikwad 2005), other HPLC methods (Kovaríkova et al. 2004; Lydia et al. 2005), liquid chromatography-electrospray ionizationtandem mass spectrometry (LC-ESI-MS, Kim et al. 2004a, b; Salem et al. 2004), liquid chromatographymass spectroscopy (LC-MS, Chang et al. 2004; Yuzuak et al. 2007), and other liquid chromatographic techniques (Pathare et al. 2007; Sukumar et al. 2005), thin layer chromatography (TLC) (Valentina et al. 2013; Gumieniczeka et al. 2009), polarographic determination (Ma et al. 2005), square-wave voltammetric technique (Suslu and Altinoz 2011). Methods have also been developed for the estimation of GLM in combination with other drugs simultaneously in pharmaceutical formulations by RP-HPLC techniques (Deepti et al. 2008; Ravi et al. 2011; El-Enany et al. 2012). From the literature survey, it was concluded that HPLC methods have been used most extensively for analysis of GLM (Bonfilio et al. 2010).

Most of the earlier methods are not ideal since they are time-consuming, have high limits of detections, use of surplus organic solvents, strenuous sample preparation, involve expensive instrumentation and long chromatographic run times. In recent years, dissolution studies have emerged in the pharmaceutical field as a very imperative tool based on the reality that for a drug to be absorbed and available to the systemic circulation, it must previously be solubilized. Consequently, the dissolution studies are used not only to evaluate batch-to-batch consistency of drug release from solid dosage forms, but also in several crucial stages of formulation development, for screening and proper assessment of different formulations. Moreover, the information obtained from in vitro dissolution studies has been used for the successful characterization of the in vivo behavior of drugs. To our knowledge, there is no specific RPHPLC method for quantification and assessing dissolution rate profile for GLM in self-nanoemulsifying powder (SNEP) formulation.

The main purpose of the present work was to develop and validate a simple RP-HPLC method to be applied for the quantification and dissolution studies of GLM in SNEP formulation. The developed and validated method is rapid, reproducible with simple mobile phase, troublefree sample preparation steps, improved sensitivity and a short chromatographic run time, which therefore serves as a tool for the quality control of pharmaceutical dosage forms.

\section{Experimental}

\section{Materials and methods}

Glimepiride was a gift sample from Dr. Reddy's Laboratories Ltd, Hyderabad, India and was used without further purification. Amaryl ${ }^{\circ}$ tablets containing $2 \mathrm{mg}$ GLM as per labels claim (manufactured by Sun Pharmaceutical Industries, Mumbai, Maharashtra, India) were obtained from a local pharmacy. Methanol and acetonitrile of HPLC grade were procured from E. Merck Ltd., Mumbai, India. Sodium hydroxide, sodium dihydrogen phosphate, ortho phosphoric acid, TEA of AR grade, sesame oil, Tween ${ }^{\circ}$ 20, PEG 400, and Aerosil ${ }^{\circ} 200$ were obtained from SD Fine Chemicals Ltd. Mumbai, India. Purified HPLC grade water was obtained by reverse osmosis and filtration through a Milli- $Q^{\circ}$ system (Millipore, Milford, MA, USA), and the same was used to prepare all solutions. 


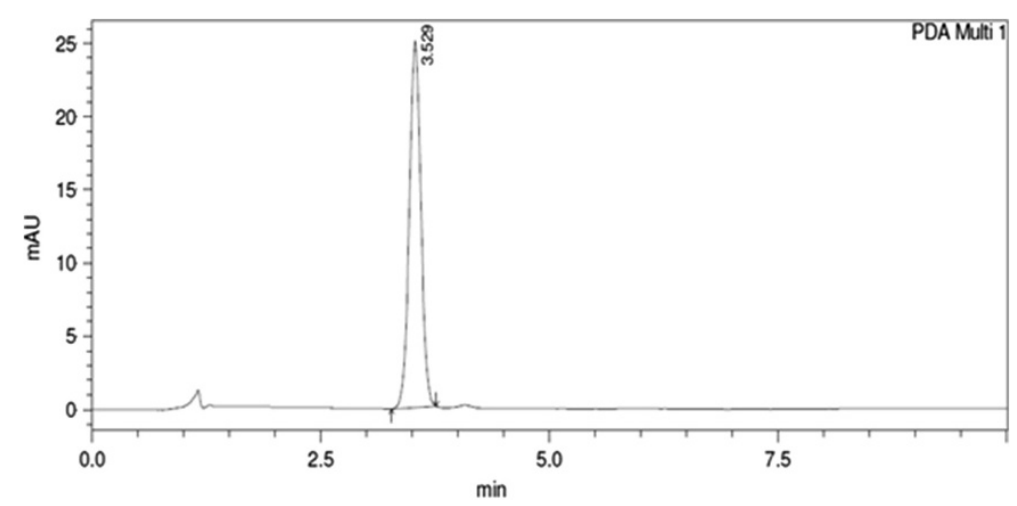

Figure 2 Typical chromatogram of GLM standard.

HPLC instrumentation and chromatographic conditions The HPLC analysis was carried out on Shimadzu HPLCLC-20 AD series binary gradient pump with Shimadzu SPD-M20A detector (Tokyo, Japan). The column used was Phenomenex Luna C18 (2) $(250 \times 4.6 \mathrm{~mm})$ packed with $5 \mu \mathrm{m}$ particles. The injection volume of sample $20 \mu \mathrm{L}$ was used in all the experiments. In an isocratic mobile phase containing acetonitrile and $0.2 \mathrm{M}$ phosphate buffer ( $\mathrm{pH} 7.4), 40: 60(v / v)$ was pumped through the column with a flow rate of $1 \mathrm{~mL} / \mathrm{min}$ and the quantification was achieved at $228 \mathrm{~nm}$ using PDA detector. The mobile phase was filtered through a $0.45-\mu \mathrm{m}$ membrane filter and degassed before use.

\section{Methods}

Preparation of liquid self-nanoemulsifying drug delivery system and self-nanoemulsifying powder formulation

The vehicle (sesame oil), surfactant (Tween $\left.{ }^{\circ} 20\right)$, and cosurfactants (PEG 400) were selected for the preparation of self-nanoemulsifying drug delivery systems (SNEDDS). The formulation was prepared by dissolving GLM in the mixture of oil, surfactant, and co-surfactant accurately weighed in glass vials. Then, the components were mixed by gentle stirring and vortex mixing using vortex mixer (REMI CM 101DX, REMI Equipment, Mumbai, India) and heated at $50{ }^{\circ} \mathrm{C}$ in an isothermal water bath to obtain a homogenous isotropic mixture. The final formulation was inspected for signs of turbidity or phase separation and drug precipitation prior to self-emulsification. The formulation was stored at ambient temperature for further use. The simplest technique to convert liquid SNEDDS to SNEP is, by adsorption onto the surface of carriers. In the present study, Aerosil 200 was used as an adsorption carrier. SNEP was prepared by mixing liquid SNEDDS containing GLM with Aerosil ${ }^{\circ} 200$ in 1:1 proportion. In brief, liquid SNEDDS was added drop wise over Aerosil ${ }^{\circ} 200$ contained in a broad porcelain dish. After each addition, mixture was homogenized using glass rod to ensure uniform distribution of formulation. Resultant damp mass was passed through sieve no. 120 and dried at ambient temperature. Then the dose-equivalent free-flow powder was filled into hard gelatin capsules and stored until further use.

\section{Preparation of stock and standard solutions}

A stock solution of $100 \mu \mathrm{g} / \mathrm{mL}$ was prepared by transferring $10 \mathrm{mg}$ of GLM into a $100-\mathrm{mL}$ volumetric flask; $30 \mathrm{~mL}$ of $0.1 \mathrm{~N} \mathrm{NaOH}$ was added, and the mixture was sonicated to dissolve and the final volume of the solution was made up with HPLC grade methanol. The stock solution was protected from light using aluminum foil and aliquots of the standard stock solution of GLM were transferred using A-grade bulb pipettes into $10-\mathrm{mL}$ volumetric flasks and the solutions were made up to volume with mobile phase to give final concentrations in the range of $0.2,0.4,0.8,0.9,1.2,1.4$, and $2 \mu \mathrm{g} / \mathrm{mL}$.

\section{Method validation}

The optimized chromatographic method was completely validated according to the procedures described in $\mathrm{ICH}$ guidelines Q2 (R1) for the validation of analytical methods.

\section{Table 1 Optimized chromatographic conditions}

\begin{tabular}{ll}
\hline Stationary phase (column) & $\begin{array}{l}\text { Phenomenex luna C1 } \\
(\mathbf{2 5 0 \times 4 . 5} \mathbf{~ m m}) \text { packed } \\
\text { with } \mathbf{5} \boldsymbol{\mu m} \text { particles }\end{array}$ \\
\hline Mobile phase & $\begin{array}{l}\text { Acetonitrile, 0.2 M phosphate } \\
\text { buffer }(\mathrm{pH} 7.4) 40: 60(\mathrm{~V} / \mathrm{v})\end{array}$ \\
Detection wave length $(\mathrm{nm})$ & 228 \\
Run time (min) & 10 \\
Flow rate $(\mathrm{mL} / \mathrm{min})$ & 1 \\
Volume of injection loop $(\mu \mathrm{L})$ & 20 \\
Column temperature & Ambient \\
Glimepiride $R_{t}(\mathrm{~min})$ & 3.543
\end{tabular}




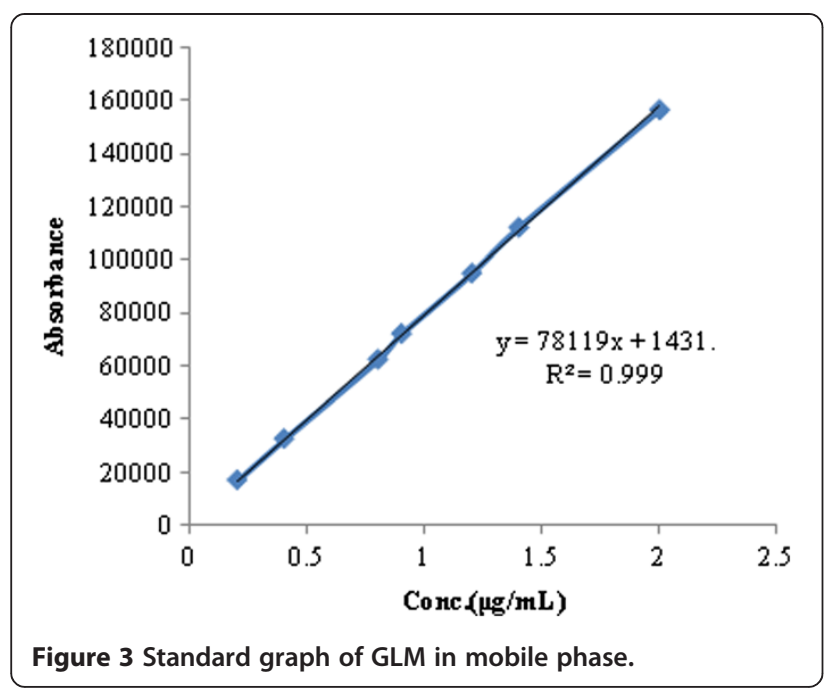

Linearity and range

Standard stock solution was diluted to prepare solutions containing 0.2 to $2 \mu \mathrm{g} / \mathrm{mL}$ of the GLM. The solutions were injected in triplicate into the HPLC column, keeping the injection volume constant $(20 \mu \mathrm{L})$.

\section{System suitability}

Twenty microliters of the standard solution $(1.2 \mu \mathrm{g} / \mathrm{mL})$ was injected six times under optimized chromatographic conditions to evaluate the suitability of the system.

\section{Precision}

Three injections, of two different concentrations (1.2 and $1.4 \mu \mathrm{g} / \mathrm{mL}$ ), were given on the same day and the values of percent relative standard deviation (\%RSD) were calculated to determine intra-day precision. These studies were also repeated on different days to determine inter-day precision.

\section{Accuracy}

Accuracy was evaluated by fortifying a mixture of common excipient solutions with two known GLM reference standards. The recovery of the added drug was determined.

Table 2 Linearity parameter for glimepiride

\begin{tabular}{ll}
\hline Conc. $(\boldsymbol{\mu g} / \mathbf{m L})$ & Area \\
\hline 0.2 & $17,055.22$ \\
0.4 & 32,679 \\
0.8 & $62,567.25$ \\
0.9 & $72,346.5$ \\
1.2 & 95,187 \\
1.4 & 112,383 \\
2.0 & 156,821 \\
\hline
\end{tabular}

Table 3 System suitability parameters

\begin{tabular}{llll}
\hline Concentration & Injection & Area & $\boldsymbol{R}_{\boldsymbol{t}}(\mathbf{m i n})$ \\
\hline & Inj-1 & 95,187 & 3.54 \\
& Inj-2 & 95,245 & 3.52 \\
$1.2 \mu \mathrm{g} / \mathrm{mL}$ & Inj-3 & 95,307 & 3.52 \\
& Inj-4 & 95,377 & 3.53 \\
& Inj-5 & 95,442 & 3.54 \\
& Inj-6 & 95,517 & 3.52 \\
& Mean & $95,345.83$ & 3.528 \\
& SD & 123.62 & 0.00983 \\
& \%RSD & 0.129 & 0.278 \\
& Tailing factor & 0.899 & \\
& Plate count & $1,771.634$ & \\
\hline
\end{tabular}

\section{Specificity}

To ascertain specificity, a placebo solution was prepared using the same excipients as those are present in the marketed tablet without GLM. Placebo solution was injected into the HPLC system under the optimized test conditions and the chromatogram was recorded. Responses of the peaks were noted for any possible interferences of the excipient at the retention time of the GLM.

\section{Limit of detection and limit of quantification}

The limit of detection (LOD) is the lowest amount of analyte that can be detected in a sample, but not necessarily quantified, under the stated experimental conditions. The limit of quantification (LOQ) was identified as the lowest plasma concentration of the standard curve that could be quantified with acceptable accuracy, precision, and variability. They are determined by the signalto-noise method.

\section{Assay}

For the analysis of marketed formulation Amaryl ${ }^{\circ}, 20$ tablets were accurately weighed and powdered. The powder equivalent to $1.0 \mathrm{mg}$ of GLM was weighed accurately and transferred to a $10-\mathrm{mL}$ volumetric flask containing $1.0 \mathrm{~mL}$ of $0.1 \mathrm{~N} \mathrm{NaOH}$. The mixture was sonicated to dissolve, made up the volume with methanol and filtered through a $0.45-\mu \mathrm{m}$ membrane filter. Aliquots of

Table 4 Reproducibility and precision data evaluated through intra-day and inter-day studies

\begin{tabular}{|c|c|c|c|c|}
\hline \multirow{2}{*}{$\begin{array}{l}\text { Conc. } \\
(\mu \mathrm{g} / \mathrm{mL})\end{array}$} & \multicolumn{2}{|l|}{ Intra-day $(n=3)$} & \multicolumn{2}{|l|}{ Inter-day $(n=3)$} \\
\hline & $\begin{array}{l}\text { Mean peak area } \pm \text { SD } \\
(n=3)\end{array}$ & \%RSD & $\begin{array}{l}\text { Mean peak } \\
\text { area } \pm \text { SD }(n=3)\end{array}$ & \%RSD \\
\hline 1.2 & $95,187 \pm 605$ & 0.63 & $96,391 \pm 426$ & 0.44 \\
\hline 1.4 & $112,849 \pm 1,077$ & 0.95 & $115,782 \pm 1,121$ & 0.96 \\
\hline 2.0 & $165,844 \pm 1,317$ & 0.79 & $169,267 \pm 541$ & 0.319 \\
\hline
\end{tabular}


Table 5 Recovery studies

\begin{tabular}{llll}
\hline $\begin{array}{l}\text { Actual conc. } \\
(\boldsymbol{\mu} \mathbf{g} / \mathrm{mL})\end{array}$ & $\begin{array}{l}\text { Calculated conc. } \\
(\boldsymbol{\mu} \mathbf{g} / \mathrm{mL}) \pm \mathrm{SD}(\boldsymbol{n}=\mathbf{3})\end{array}$ & \%RSD & \%Recovery \\
\hline 1.2 & $1.1983 \pm 0.00153$ & 0.127 & 99.87 \\
1.4 & $1.403 \pm 0.01058$ & 0.754 & 100.3 \\
\hline
\end{tabular}

this standard solution were transferred using A-grade bulb pipettes into $10-\mathrm{mL}$ volumetric flasks, and the solutions were made up to volume with mobile phase to give final concentration of $10 \mu \mathrm{g} / \mathrm{mL}$. The above solution was then analyzed for the content of GLM using the proposed method.

\section{Dissolution release study of pure drug, marketed and SNEPS formulation}

The dissolution studies of GLM-loaded SNEP formulation was performed in a USP-II dissolution test apparatus (DS 8000, LABINDIA, Mumbai, India). The dissolution studies were conducted according to the dissolution procedure recommended for single-entity products in $900 \mathrm{~mL}$ of $0.1 \mathrm{~N} \mathrm{HCl}(75 \mathrm{rpm})$. The temperature of the cell was maintained at $37 \pm 0.5{ }^{\circ} \mathrm{C}$ by using a thermostatic bath. At predetermined time intervals $(0$, $5,10,15,30,60,90$, and $120 \mathrm{~min})$ an aliquot $(5 \mathrm{~mL})$ of the sample was withdrawn from each vessel and immediately replaced with an equal volume of fresh medium to maintain sink conditions. The samples collected were filtered through a membrane filter $(0.45 \mu \mathrm{m})$ and further analyzed by HPLC. In order to obtain the dissolution profile, the cumulative percentage of drug released was plotted against time (min).

\section{Results and discussion}

Method development

Development of new HPLC methods are often useful in regular quality control assessment of pharmaceuticals which may convey relevant information in establishing

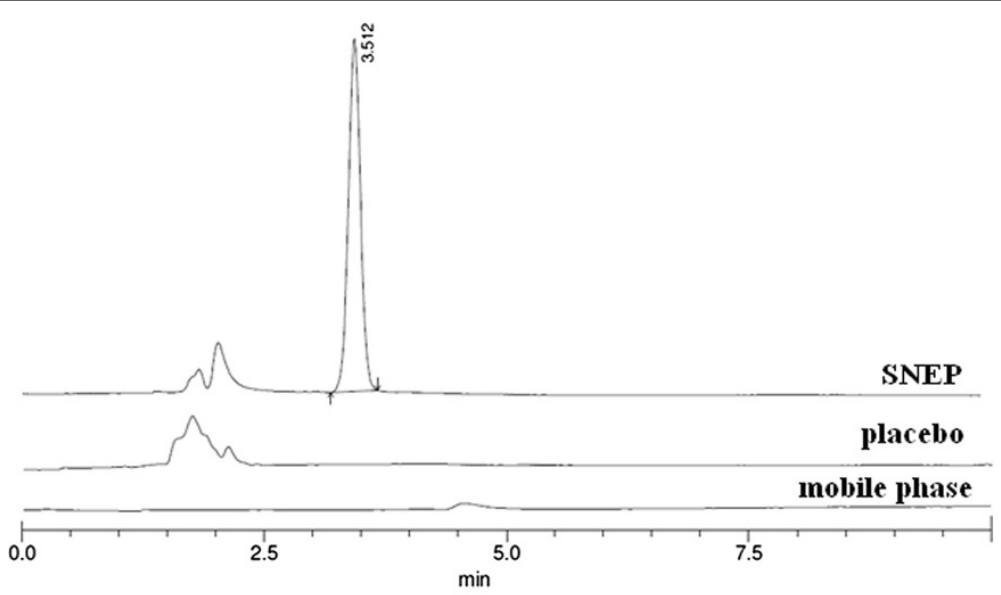

A

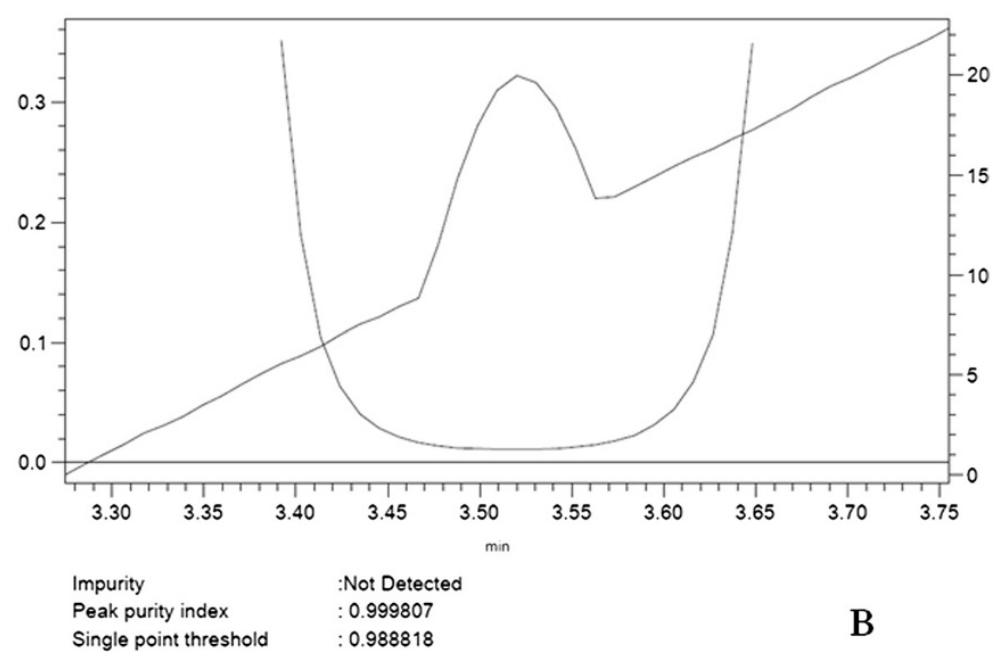

Figure 4 Specificity chromatograms (A) and peak purity index of SNEP (B). SNEP (i), placebo (ii), and mobile phase (iii). 
optimal experimental conditions for the better usage of drugs. In this study, a simple, specific, selective, and accurate RP-HPLC method to quantify and to study drug release profile of GLM was developed and validated according to $\mathrm{ICH}$ guidelines. Acetonitrile and $0.2 \mathrm{M}$ phosphate buffer ( $\mathrm{pH}$ 7.4) in different proportions were tried, and finally, a ratio of acetonitrile - $0.2 \mathrm{M}$ phosphate buffer ( $\mathrm{pH}$ 7.4) (40:60) - was selected as an appropriate combination which gave good resolution and acceptable system suitability parameters. The chromatogram of working standard of GLM solution was shown in Figure 2. Optimized chromatographic conditions were given in Table 1. The mobile phase was filtered through a $0.45-\mu \mathrm{m}$ membrane filter before use. The contents were finally transferred to solvent reservoir of the LC20AD pump and purged the solvent line with $30 \mathrm{~mL}$ of fresh mobile phase.

\section{Linearity}

The required test samples were prepared freshly using the stock solution in the range of 0.2 to $2 \mu \mathrm{g} / \mathrm{mL}$ (GLM). Triplicate $20-\mu \mathrm{L}$ injections were made for each concentration and were analyzed under the conditions optimized chromatographic conditions. A calibration curve was obtained by plotting the response (peak area) versus concentration of drug and represented in Figure 3. Linearity parameter for GLM was given in Table 2 .

\section{System suitability}

System suitability tests were carried out on freshly prepared standard stock solutions of GLM and it was calculated by determining the standard deviation of GLM standards by injecting in six replicates at short time intervals and the peak areas were recorded and represented in Table 3.

\section{Precision}

The precision of the method was demonstrated by interday and intra-day variation studies. In the intra-day studies, solutions of the standard and the sample were repeated thrice in a day, and \%RSD for the response factor was calculated; the results were tabulated in Table 4 . The \%RSD values in the two cases were $<2 \%$, which indicates that the method was sufficiently precise.
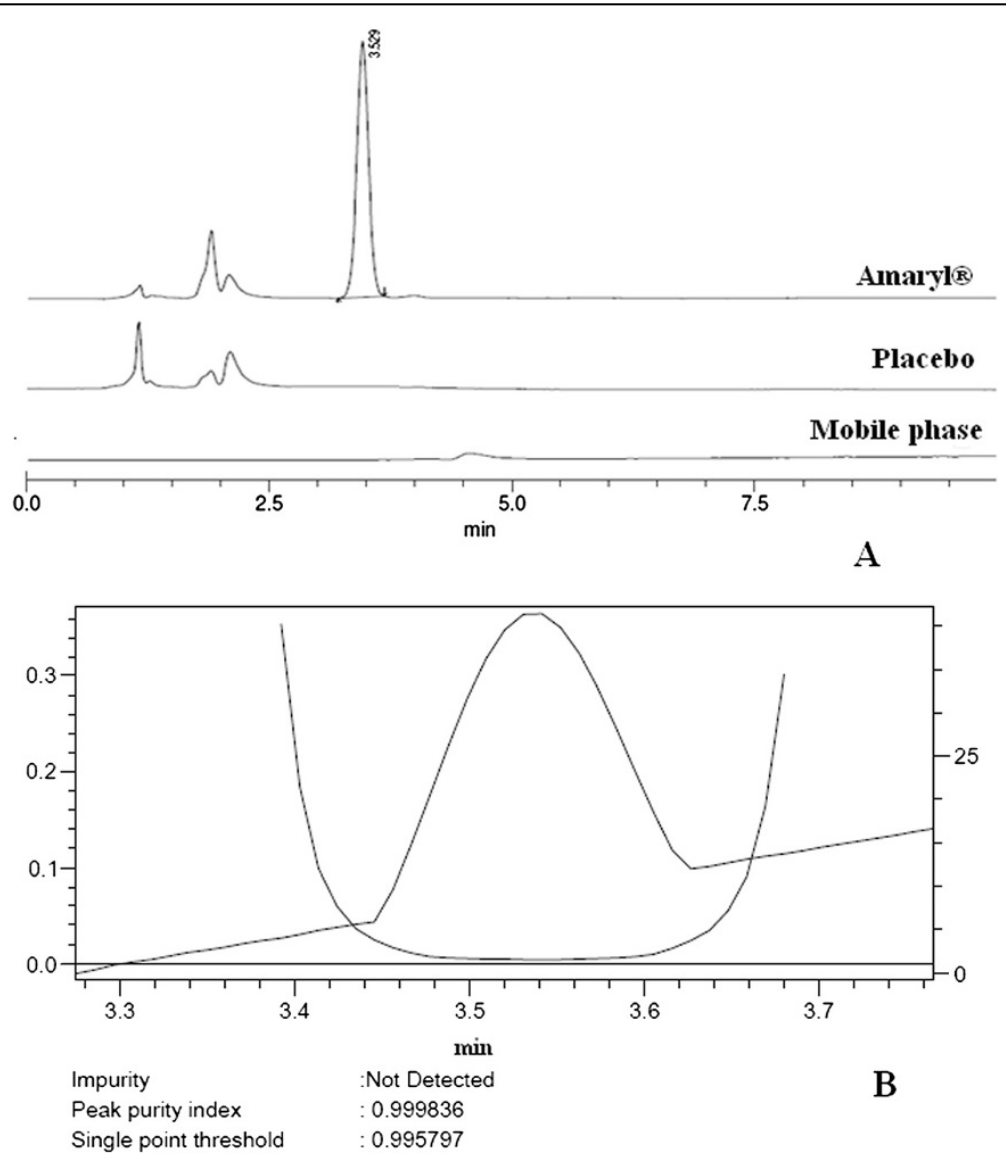

Figure 5 Specificity chromatograms (A) and peak purity index of Amaryl $\left.\right|^{\circledR}$ (B). Amary ${ }^{\circledR}$ (i), Placebo (ii), and Mobile phase (iii). 


\section{Accuracy}

The accuracy of the method was determined by recovery experiments. The recovery studies were performed by using standard addition method. GLM reference standards were accurately weighed and added to the fixed concentration of self-nanoemulsifying powder at different concentration levels $(1.2$ and $1.4 \mu \mathrm{g} / \mathrm{mL})$. Percent recovery was calculated by comparing the area before and after the addition of reference standard. The recovery studies were performed in triplicate. Percent recovery was within the range of $99.8 \%$ to $100.3 \%$ as shown in Table 5 for GLM which indicates that the method was accurate.

\section{Specificity and selectivity}

Specificity was tested against standard compounds and possible interference peaks in the presence of placebo under optimized test conditions. The comparison of the chromatograms of the placebo mixture and the spiked drug solution revealed that there were no additional peaks co-eluting with the peaks of GLM in the sample solution. No interference from the placebo was observed at the retention time of the GLM (Figure 4A and Figure 5A). Therefore, it was concluded that the method is specific and can assess unequivocally the analyte of the interest in the presence of possible interferences. Peak purity indices for SNEP and Amaryl ${ }^{\circ}$ are shown in Figures $4 \mathrm{~B}$ in $5 \mathrm{~B}$.

\section{Limit of detection and limit of quantification}

Standard stock solutions of GLM $(1 \mathrm{mg} / \mathrm{mL})$ were prepared. Standard solutions of GLM $(0.2,0.4,0.8,0.9,1.2$, 1.4 , and $2 \mu \mathrm{g} / \mathrm{mL}$ ) were prepared by diluting the standard stock solutions with mobile phase. The LOD and LOQ GLM under the present chromatographic conditions were estimated at a signal-to-noise ratio $(\mathrm{S} / \mathrm{N})$ of 3:1 and 10:1 respectively, by injecting a series of diluted solutions with known concentrations. The LOD and

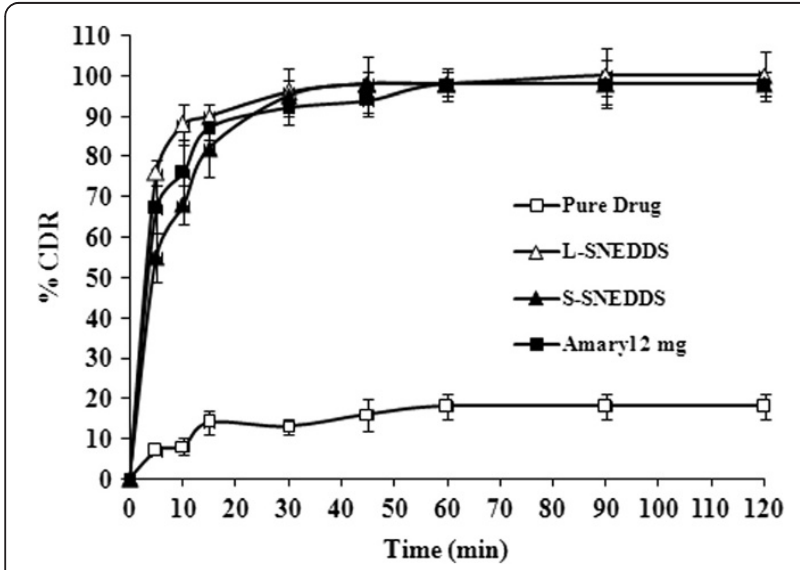

Figure 6 Drug release profile of SNEP, liquid SNEDDS, and Amaryl ${ }^{\circledR}$.
Table 6 Robustness study

\begin{tabular}{lllll}
\hline $\begin{array}{l}\text { System suitability } \\
\text { parameters (variations) }\end{array}$ & $\begin{array}{l}\text { \%RSD peak } \\
\text { area }(\boldsymbol{n}=6)\end{array}$ & $\begin{array}{l}\text { Mean tailing } \\
\text { factor }(\boldsymbol{n}=\mathbf{6})\end{array}$ & $\begin{array}{l}\text { Mean } \boldsymbol{R}_{\boldsymbol{t}} \\
(\mathbf{m i n})(\boldsymbol{n}=\mathbf{6})\end{array}$ \\
\hline Varied $\mathrm{pH}( \pm 0.2 \%)$ & 7.2 & 1.354 & 0.875 & 0.321 \\
& 7.6 & 1.371 & 0.858 & 0.336 \\
$\begin{array}{l}\text { Mobile phase ratio } \\
( \pm 20 \mathrm{~V} / \mathrm{V})\end{array}$ & $60: 40$ & 1.362 & 0.891 & 0.338 \\
& $20: 80$ & 1.348 & 0.915 & 0.346 \\
\hline
\end{tabular}

LOQ for GLM were found to be 0.38 and $1.17 \mu \mathrm{g} / \mathrm{mL}$, respectively.

\section{Robustness}

Robustness of the method was checked by making slight changes in chromatographic conditions like mobile phase ratio, $\mathrm{pH}$ of buffer, flow rate. It was observed that there were no noticeable changes in chromatograms, which demonstrated that the developed RP-HPLC method is robust and is represented in Table 6.

\section{Assay of marketed tablets}

The results of assay of marketed tablets Amaryl ${ }^{\circledR}$ as described earlier showed good conformity with the label claim and the assay values are represented in Table 7.

\section{In vitro dissolution study}

A dissolution release study was carried out for liquid SNEDDS, SNEP of GLM, and marketed formulation Amaryl $^{\circ}$. As evident from the drug release profiles, the $\%$ CDR of pure drug, liquid SNEDDS, SNEP and Amaryl ${ }^{\circ}$ were $14.68 \pm 3.88,90.36 \pm 3.74,82.22 \pm 7.32$, and $87.3 \pm$ 2.84 , respectively at the 15 th $\mathrm{min}$. The results indicate instantaneous and remarkably higher and faster dissolution rate of GLM from SNEP, liquid SNEDDS, and marketed formulation compared to pure drug. The \% CDR profile for liquid SNEDDS, SNEP of GLM, and Amaryl $^{\circledR}$ are shown in Figure 6.

\section{Conclusion}

The proposed method was rapid, accurate, precise, and sensitive for the quantification of GLM from its pharmaceutical dosage forms. The method relies on the use of simple working procedure; hence, this method can be routinely employed in quality control for analysis of GLM in pharmaceutical dosage forms and dissolution studies.

Table 7 Assay of GLM marketed tablets Amaryl ${ }^{\circledR}(n=3)$

\begin{tabular}{llll}
\hline $\begin{array}{l}\text { Label claim } \\
(\mathbf{m g} / \mathrm{tab})\end{array}$ & $\begin{array}{l}\text { Mean estimated } \\
\text { amt }(\mathbf{m g})\end{array}$ & $\begin{array}{l}\text { \%Label } \\
\text { claim } \pm \text { SD }\end{array}$ & \%RSD \\
\hline 2 & 1.995 & $99.75 \pm 0.4712$ & 0.4723 \\
2 & 2.0048 & $100.24 \pm 0.5234$ & 0.5221 \\
2 & 2.0064 & $100.32 \pm 0.4372$ & 0.4358 \\
\hline
\end{tabular}




\section{Competing interests}

The authors declare that they have no competing interests.

\section{Acknowledgements}

The authors greatly acknowledge the receipt of pure GLM from Dr. Reddy's Laboratories Ltd, Hyderabad, India and are also thankful to Dr. P. Rajeshwar Reddy, Chairman, School of Pharmacy (Anurag Group of Institutions) Hyderabad for providing research facilities throughout the project work.

\section{Author details}

${ }^{1}$ Department of Pharmaceutics, School of Pharmacy, Nalla Narasimha Reddy Educational Society's Group of Institutions, Hyderabad -500088, AP, India. ${ }^{2}$ Department of Pharmaceutics, School of Pharmacy, Anurag Group of Institutions, Hyderabad -500088, AP, India. ${ }^{3}$ Department of Pharmaceutics, National Institute of Pharmaceutical Education and Research (NIPER), Hyderabad 500 037, AP, India.

Received: 10 September 2013 Accepted: 25 February 2014 Published online: 02 April 2014

\section{References}

Altinoz S, Tekeli D (2001) Analysis of glimepiride by using derivative UV spectrophotometric method. J Pharm Biomed Anal 24(3):507-515

Bell DS (2004) Practical Considerations and Guidelines for Dosing Sulfonylureas in Monotherapy or Combination Therapy. Clin Ther 26(11):1714-1727

Bonfilio Rudy MD, Araújo D, Benjamim M, Regina Nunes SH (2010) A Review of Analytical Techniques for Determination of Glimepiride: Present and Perspectives. Ther Drug Monit 32(5):550-559

Davis SN (2004) The Role of Glimepiride in the Effective Management of Type 2 Diabetes. J Diabetes Complicat 18(6):367-376

Deepti J, Surendra J, Deepak J, Maulik A (2008) Simultaneous Estimation of Metformin Hydrochloride, Pioglitazone Hydrochloride, and Glimepiride by RP-HPLC in Tablet Formulation. J Chromatogr Sci 46:501-504

Drummer OH, Kotsos A, McIntyre IM (1993) J Anal Toxicol 17:225-229

El Deeb S, Schepers U, Watzig H (2006) Fast HPLC method for the determination of glimepiride, glibenclamide, and related substances using monolithic column and flow program. J Sep Sci 29(11):1571-7

El-Enany NM, Abdelal AA, Belal FF, Itoh YI, Nakamura MN (2012) Development and validation of a reversed phase-HPLC method for simultaneous determination of rosiglitazone and glimepiride in combined dosage forms and human plasma. Chem Cent J 6(9):1-10

Goodman \& Gilman (2008) Manual of Pharmacology and Therapeutics. Mc Graw Hill, New York, pp 1037-1058

Gumieniczeka A, Hopkałab H, Bereckab A (2009) Ant diabetic Drugs: HPLC/TLC Determination. Encyclopedia of Chromatography, $3^{\text {rd }}$ edn. vol II.

Jingar JN, Rajput SJ, Dasandi B, Rathnam S (2008) Development and Validation of LC-UV for Simultaneous Estimation of Rosiglitazone and Glimepiride in Human Plasma. Chromatographia 67(11-12):951-955

Khan IU, Aslam F, Ashfaq M, Asghar MN (2009) Determination of Glimepiride in Pharmaceutical Formulations Using High-Performance Liquid Chromatography and First-Derivative Spectrophotometric Methods. J Anal Chem 64(2):171-175

Kim H, Chang KY, Lee HJ, Han SB (2004a) Determination of Glimepiride in Human Plasma by Liquid Chromatography-Electro spray Ionization Tandem Mass Spectrometry. Bull Korean Chem Soc 25(1):109-114

Kim H, Chang KY, Park CH, Jang MS, Lee JA, Lee HJ, Lee KR (2004b) Determination of Glimepiride in Human Plasma by LC-MS-MS and Comparison of Sample Preparation Methods for Glimepiride. Chromatographia 60(1-2):93-98

Kovaríkova P, Klimes J, Dohnal J, Tisovska L (2004) HPLC study of glimepiride under hydrolytic stress conditions. J Pharm Biomed Anal 36(1):205-9

Langtry HD, Balfour JA (1998) Glimepiride: A review of its use in the management of type 2 diabetics. Drugs 55:563-84

Lehr KH, Damm P (1990) Simultaneous Determination of the Sulphonylurea Glimepiride and Its Metabolites in Human Serum and Urine by HighPerformance Liquid Chromatography after Pre-Column Derivatization. J Chromatogr B 526(1):497-505

Lydia RK, Rita AD, Dolla KS, Chawki A, Antoine Z (2005) A Simple and Sensitive Method for Determination of Glimepiride in Human Serum by HPLC. J of Liq Chromatogr R T 28(20):3255-3263

Ma HL, Xu MT, Qu P, Ma XH (2005) Polarographic behavior and determination of glimepiride. Acta Pharmaceut Se 40(8):750-3
McCall AL (2001) Clinical Review of Glimepiride. Expert Opinion on Pharmacotherapy 2(4):699-713

Nunez M, Ferguson JE, Machacek D, Jacob G, Oda RP, Lawson GM, Landers JP (1995) Anal Chem 67:3668-3675

Pathare DB, Jadhav AS, Shingare MS (2007) RP-LC Determination of the Cis-Isomer of Glimepiride in a Bulk Drug Substance. Chromatographia 66(7-8):639-641

Ravi S, Gagan S, Darpan C, Jain PK (2011) Analytical Method Development And Validation For The Simultaneous Estimation Of Pioglitazone And Glimepiride In Tablet Dosage Form By RP-HPLC. Int J Pharm Sci Res 2(3):637-642

Roche ME, Oda RP, Lawson GM, Landers JP (1997) Capillary Electrophoretic Detection of Metabolites in the Urine of Patients Receiving Hypoglycemic Drug Therapy. Electrophoresis 18(10):1865-1874

Rosenstock J, Samols E, Muchmore DB, Schneider J (1996) Glimepiride, a New Once-Daily Sulfonylurea: A Double-Blind Placebo-Controlled Study of NIDDM Patients. Diabetes Care 19(11):1194-1199

Salem II, Idrees J, Al Tamimi JI (2004) Determination of Glimepiride in Human Plasma by Liquid Chromatography-Electro spray Ionization Tandem Mass Spectrometry. J Chromatogr B Analyt Technol Biomed Life Sci 799(1):103-9

Song YK, Maeng JE, Hwang HR, Park JS, Kim BC, Kim JK, Kim CK (2004) Determination of glimepiride in human plasma using semi-micro bore high performance liquid chromatography with column-switching. J Chromatogr B 810(1):143-149

Sujatha S, Sandhya RT, Veeresham C (2011) Determination of Glimepiride in Rat Serum by RP-HPLC Method. Am J Anal Chem 2:152-157

Suslu I, Altinoz S (2011) Determination of Glimepiride in Pharmaceutical Formulations by Square-Wave Voltammetric Method. Curr Anal Chem 7(4):333-340

Valentina T, Slavica F, Gordana P, Katarina N, Danica A (2013) TLC Determination Of Glimepiride And Its Main Impurities In Pharmaceuticals. J of Liq Chromatogr R T 36(17):2422-2430

Wanjari DB, Gaikwad NJ (2005) Reversed Phase HPLC Method for Determination of Glimepride in Tablet Dosage Form. Indian J Pharm sci 2(67):253-255

Yuzuak N, Ozden T, Eren S, Ozilhan S (2007) Determination of Glimepiride in Human Plasma by LC-MS-MS. Chromatographia 66(1):165-168

\section{doi:10.1186/s40543-014-0027-0}

Cite this article as: Mohd et al:: Development and validation of RP-HPLC method for glimepiride and its application for a novel selfnanoemulsifying powder (SNEP) formulation analysis and dissolution study. Journal of Analytical Science and Technology 2014 5:27.

\section{Submit your manuscript to a SpringerOpen ${ }^{\circ}$ journal and benefit from:}

- Convenient online submission

- Rigorous peer review

- Immediate publication on acceptance

- Open access: articles freely available online

- High visibility within the field

- Retaining the copyright to your article

Submit your next manuscript at $>$ springeropen.com 